\title{
A EUROPEAN INTEROPERABLE DATABASE (EID) TO INCREASE RESILIENCE OF CULTURAL HERITAGE
}

\author{
F. Chiabrando ${ }^{\text {a }}$, E. Colucci ${ }^{\text {a }}$, A. Lingua ${ }^{b}$, F. Matrone ${ }^{b *}$, F. Noardo ${ }^{b}$, A. Spanò ${ }^{a}$ \\ ${ }^{a}$ Department of Architecture and Design (DAD) - Politecnico di Torino Viale Mattioli 39, 10125 Torino (Italy) \\ (filiberto.chiabrando@polito.it, elisabetta.colucci@polito.it, antonia.spano@polito.it) \\ ${ }^{b}$ Department of Environment Land and Infrastructure Engineering (DIATI) - Politecnico di Torino Corso Duca degli Abruzzi 24, \\ 10129 Torino (Italy) (andrea.lingua@polito.it, francesca.matrone@polito.it, francesca.noardo@polito.it)
}

KEY WORDS: Cultural Heritage, Resilience, Database, Disaster Management, Risk

\section{ABSTRACT:}

The set of laws, actions and organizations for Cultural Heritage $(\mathrm{CH})$ protection is born in the different countries of the European Union from local cultural situations, so the ability to cope with the emergency is certainly different. In addition to the damages that can occur to cultural assets after a disaster, an inadequate emergency intervention can sometimes cause further losses to the $\mathrm{CH}$.

The effectiveness of response depends on the adequacy of advanced planning. Some countries have designed emergency plans but their databases (DBs) are fragmented, incomplete and not standardized. It is thus necessary to establish a DB for emergency assistance and maps of $\mathrm{CH}$ at risk to be compared with maps of natural hazards and risks, in order to take preventive and operational measures, as well as agree on a common terminology and international standards.

The project aims to enhance the capability of Civil Protection to prevent disasters impacts on $\mathrm{CH}$ by implementing a European Interoperable Database (EID) as supporting decision tool to understand the risk of damage to cultural assets.

The EID, starting from the international standards to represent the map objects (CityGML, INSPIRE), the classification of CH in Europe (UNESCO), in Italy (MiBACT), in Germany and in France and from risks and disasters analysis, will design, with its Conceptual Data Model, an extension of the INSPIRE UML model. This DB will also support 3D models to help finding and recognizing dispersed artworks and facilitate a post-emergency restoration, preserving thus a digital memory in case of destruction.

\section{INTRODUCTION}

Natural disasters can be seen as a serious threat for $\mathrm{CH}$ : they can cause permanent damages or the destruction of entire areas and movable and immovable cultural goods. Moreover, inadequate emergency operations can intensify what natural injuries have already done. The need to provide an immediate response can lead first responders to take wrong decision causing more damages than the ones generated by the disaster.

In the last decades, the overall cost of damages due to hazards increased as well as the numbers of events.

From this point of view, the necessity to increase efforts for a cooperation at European level carried out to protect $\mathrm{CH}$ from natural hazards is fundamental.

On the other hand, political attention is focused upon environmental issues and a marginal role is given to the protection of cultural heritage.

The emerging inefficiency in the management of cultural heritage is due to: inadequate assets knowledge; inability to evaluate the real loss and damage costs and complexity to assign an economic value to all the cultural goods outside of the market mechanisms. The actions and strategies for the protection of cultural heritage must be based upon an in-depth knowledge of the European $\mathrm{CH}$ at risk. The situation is different from a country to another and it is also related to the IT and technologies used at national level.

Taking into account past disaster, has come to the light that a well-coordinated management, good preparation and a best knowledge of the goods at risk, such as their status and their structural and other features, would reduce the errors done and as a consequence the numbers of artworks lost.

For the mitigation of natural hazard effects, the following measures need to be taken into account:

- regular monitoring and accurate maintenance of historical heritage;

- better planning and management of the territory;
- awareness campaigns and regular coordinated training;

- international cooperation and the availability of economic resources;

- legislative support.

In order to gain knowledge and share it, was created a European Project named ResCult, the attempt to create a supporting decision tool for the safeguarding of cultural assets is underway. ResCult is a project funded by the European Commission (European Civil Protection and Humanitarian Aid Operations) wich involves Politecnico di Torino with partners: SiTI, Istituto Superiore sui Sistemi Territoriali per l'Innovazione (coordinator); UNISDR, The United Nations Office for Disaster Risk Reduction; TUB, Technische Universität Berlin; CORILA, Consortium for managing research activities in the Venice Lagoon system; SDIS 04, Service Départemental d'Incendie et de Secours des Alpes de Haute-Provence (https://www.rescultproject.eu).

In this paper will be presented the first phases of the ResCult project and the structuring of the EID, the implementation and the further development are ongoing.

\subsection{The European Interoperable Database (EID)}

The ResCult project (Increasing Resilience of Cultural Heritage) aims to enhance the capability of Civil Protection to prevent or lessen disasters impacts on $\mathrm{CH}$ by defining an Integrated Interoperable Database (EID) in order to provide a unique framework for multi-stakeholders partners as Civil Protection, national Ministries, the European Union and local authorities as a supporting decision tool to understand the risk of damage to $\mathrm{CH}$ as well as its impact on cohesion, sustainable cultural tourism and engagement with local communities in protecting environment. The main features and functionalities that the proposed EID have to satisfy are:

\footnotetext{
* Corresponding author
} 
- a European Heritage Map to offer a mapping representation of the European cultural assets using information as classification, location, ownership, vulnerability, etc...;

- a cadaster to provide historical archives of disasters as their classification (fire, earthquake, flood, manmade), magnitude, technical data, damages, etc.;

- risk scenario platform that allows to view risk indicators (classes, values, weights) for various kind of threats and to produce risk maps;

- connection to 3D models acquired by a 3D multiscale survey with different level of details to preserve people memory and support post emergency restoration. In some cases there will be the possibility to visualize the 3D models through the link to an external viewer (Figure 1) in order to make available and accessible the geometry and further information.

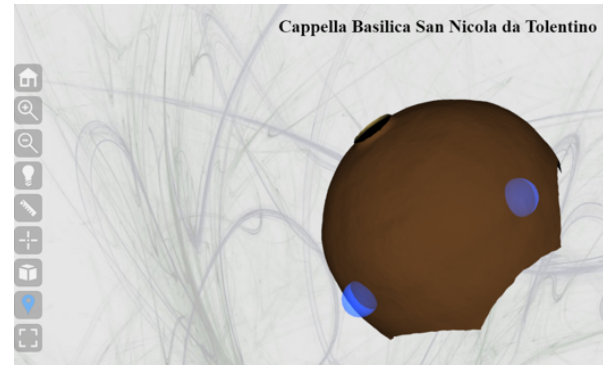

Figure 1. Display of an external link with the mesh of the dome in the case study of Tolentino's Church, damaged by the earthquake in Italy, with some hotspots for in-depth analysis. 3D visualization realized using 3DHop

(http://vcg.isti.cnr.it/3dhop/) Data processing F. Moretti, SiTI.

\section{EUROPEAN STRATEGIES FOR RISK REDUCTION}

It is necessary to define strategies for risk reduction in order to create a European Interoperable Database (EID) building a robust database of norms, ontologies, data formats and queries.

With this purpose was studied the European panorama about Disaster Risk Reduction (DRR) and prevention.

Disaster risk prevention is a development strategy that is attracting notably the increasing concern of policy makers and the general public, because of the current emphasis on various components of human and environmental security.

The European Commission in the "Communication on a Community..." established an approach for the prevention of natural and man-made disasters which defines an overall disaster prevention approach to minimize the impacts of disasters (European Commission, 2010). Member States are invited to create a common framework about risk prevention, creating methodologies for impact analysis, risk assessments, scenario development and risk management measures.

Europe has given rise to well organized disaster management practices in order to limit negative consequences of hazards. Some regions have developed valuable specialised competence for specific types of risks. A European view is essential to combine resources and finally prevent and mitigate shared risks. Moreover, these strategies, promoted by the EU, are in line with the targets and principles set forth in the Sendai Framework (UNISDR, 2017). The Sendai Framework is a 15-year, voluntary, non-binding agreement which recognizes that the State has the primary role to reduce disaster risk but that responsibility should be shared with other stakeholders including local government and the private sector. It is linked to the Sustainable Development Goals (United Nations, 2015) in which cultural heritage is fully included in the objectives of 2030 Sustainable Development Agenda linked to poverty, sustainable cities and climate action.
The Sendai Framework also highlights 4 priorities for action, key elements for ResCult Project: Understanding Risk, Strengthen DRR Governance, Invest in DRR, Enhance Preparedness. Cultural Heritage is also clearly considered in the monitoring process of the Sendai Framework with the Indicator C6: Direct economic loss to cultural heritage damaged or destroyed attributed to disasters. ResCult IED will be able to contribute of this objective.

\subsection{Protection of Cultural Heritage}

It is well known, in this risk prevention framework, which connects cultural heritage to risks and hazards, that natural and man-made disasters are the main threat that affect movable and immovable heritage. Many $\mathrm{CH}$ are compromised by inadequate emergency plans, in that regard the necessity to create planning and rehabilitation schemes for recovery, sensitive to cultural heritage, and emergency measures is essential. The protection of $\mathrm{CH}$ is a marginal issue for politicians and governments in most European countries. Some countries have designed a $\mathrm{CH}$ databases, but it's not related to hazards and risks assessment processes and risk management approaches and tools; they are fragmented, incomplete, not standardized, not harmonized. Moreover, these databases don't contain a whole map of potential natural hazards related to cultural heritage across the European territory. The maps of the European $\mathrm{CH}$ at risk connected to maps of natural hazards and risks symbolise the necessity to estimate risks and could support to predict the catastrophes entity. The role of disaster prevention is crucial in order to safeguard cultural heritage (Drdácký et al, 2007). The European Commission has been promoting several international research projects regarding possible preventive measures to cope natural and man-made disasters and their effects; ResCult project is one of these projects and is not alien to the scenario above defined.

\subsection{Risk prevention}

As explained in the previous paragraph, the risk prevention is one of the main phases in the strategy plan for risk reduction connected to built heritage and artworks.

The heritage conservation field places great importance on the use of principles in guiding practitioners to appropriate interventions for heritage properties. ICOMOS (International Council on Monuments and Sites), starting from the Charter of Venice (1964), has developed charters and guidelines in the areas of cultural tourism, underwater archaeology, historic towns, archaeological heritage management, historic gardens, recording and documentation, training and education, and, in the context of the World Heritage Convention, authenticity. This represents one of the attempt to draft a set of universal principles (ICOMOS, 1998). A more recent document concerning cultural values and heritage conservation is the FARO Convention (Council of Europe, 2005). It defines cultural legacy as a collective Europe legacy, to preserve and safeguard, inasmuch "cultural heritage is a group of resources inherited from the past which people identify, independently of ownership, as a reflection and expression of their constantly evolving values, beliefs, knowledge and traditions" (Council of Europe, 2005).

\section{STANDARDS FOR THE INTEROPERABILITY}

\subsection{Standard to represent Cartographic Objects}

In order to ensure an effective interoperability of the DB, to obtain a comprehensive model that could represent all the information useful for the ResCult analyses and to provide the 
chance to suitably represent the richness and complexity of $\mathrm{CH}$ to the connected risks in an interoperable and standard compliant map, four mapping international standards have been analyzed (Figure 2). INSPIRE (compulsory by 2020) and CityGML have been selected, according to completeness, updating, extension possibility, international acknowledgement.

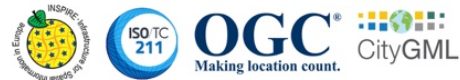

Figure 2. Standards analysed for the EID

CityGML is an open data model and XML-based format for the storage and exchange of virtual 3D city models. It is an application schema for the Geography Markup Language version 3.1.1 (GML3), the extendible international standard for spatial data exchange issued by the Open Geospatial Consortium (OGC) and the ISO TC211. The aim of the development of CityGML is to reach a common definition of the basic entities, attributes, and relations of a 3D city model. This is especially important with respect to the cost-effective sustainable maintenance of $3 \mathrm{D}$ city models, allowing the reuse of the same data in different application fields (OGC, 2014).

As this standard is based on ISO TC 211 and OGC concepts, it was a natural candidate for the modeling of 3D Buildings in INSPIRE.

So, the use of existing standard data models and ontologies in the geographic information have been the base for defining the ResCult conceptual model that could be considered as an extension of the INSPIRE Data model.

In this way data can be shared at European level, the fulfillment of the database will be easier for all the users and, on these bases, a risk map with a standard symbology for all Member States could be produced.

First of all, to perform all the ResCult analysis, it is necessary to represent both the $\mathrm{CH}$ and the land features, describing the urban environment or the landscape where the $\mathrm{CH}$ items are located.

Of course, the position of a cultural asset is connected to the related vulnerability to risk factors. Moreover, the informative contents embedded in $\mathrm{CH}$ should enable to build further increasing resilience. They are all ascertained key points.

The main difference between the INSPIRE standard and City GML is the level of detail they aim to reach and their original scope: CityGML aims at representing urban objects with a high level of detail (approximately scale 1:500), for supporting the city management. On the other hand, INSPIRE should support international trans-boundary environmental policies in Europe; therefore, the level of detail is lower, and several entities concerning environmental subject are included.

A further purpose of the INSPIRE data model is to obtain a harmonized spatial information as reference for the Community environmental policies and activities that may have an impact on the environment. For this reason, several entities related to the risk, the hazard and the necessity to protect some specific areas are included in the INSPIRE data model, besides the usual cartographic entities for mapping the land.

Since the INSPIRE data model (DM) will be the base for defining the ResCult DM, the INSPIRE themes of the three annexes (Figure 3) have been considered as base, even if they are often replaced with the CityGML classes, especially for what concerns the cartographic object representing the cultural entity to be protected.

As it is possible to read in the INSPIRE data Specification, the theme "Building" (INSPIRE, 2013) is modelled on the data specification for "Building" in CityGML, so that a harmonization between the two specification is easy, being one the base for the other.

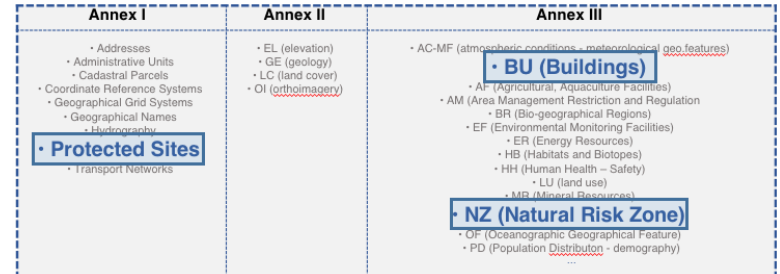

Figure 3. INSPIRE Annexes and main themes considered

(Protected Site, Buildings and Natural Risk Zone)

Whereas the data theme "Protected site" is more intended to represent sites having a specific vulnerability and the cultural value, that have to be extended with further details, is however foreseen as a reason for considering an area a protected site. Similarly, for theme "Natural Risk Zone" only the natural risks are represented in IINSPIRE DM, so details concerning other kind of human and technological risks will be implemented.

Finally, in the INSPIRE data model a theme "NaturalRiskZone" (INSPIRE, 2014) is present. Again, being the aim of INSPIRE the environmental protection, only the natural risks are represented. However, the structure is suitable for managing also the risks or hazards deriving from other kinds of phenomena or activities, for example the man-made or technological risks and for ResCult, this theme is employed, extending the classification regarding natural hazards.

3.1.1 3D models and the Level of Details: The open data model City GML is also aimed for the storage and exchange of virtual 3D city models (OGC, 2012). It specifies the semantic values of city objects for the 3D representation and here several geometries can be associated to the same object for obtaining a multi-representation, based on time, on different reconstruction hypotheses, or different Levels of Details (LoDs).

The concept of LoDs (Figure 4), as implemented in CityGML is an essential issue for ResCult: in fact, different levels of detail in the representation of the city and the landscape enable different levels of scale in the analysis of the data. The different levels of detail for the modeling of buildings are:

- LoD 0 that offers a 2D model for buildings has been included in the latest version of City GML;

- LoD 1 with block models (flat roofs);

- LoD 2 with the shape of roofs;

- LoD 3 with accurate description of exterior (including openings: doors and windows);

- LoD 4: interior model.

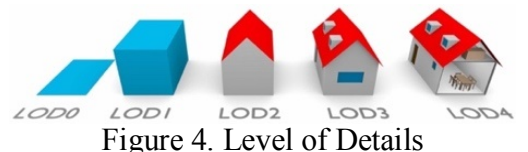

This concept, in the standard, considers the accuracy of the represented features, which is indicative of the representation scale. For instance, the LoD4 generally respects a $0.2 \mathrm{~m}$ accuracy, which is used for 1:1000 representation scales. Nevertheless, a reference scale of 1:500 can be considered as maximum foreseen detail, which is used for the historical city centers maps. So, the concept of LoDs, as implemented in CityGML is an essential issue for the ResCult project and the DB: different levels of detail in the representation of the city and the landscape (Figure 5) enable different levels of scale in the analysis of the data and could be really useful during an emergency even or during a post-disaster recovery. 


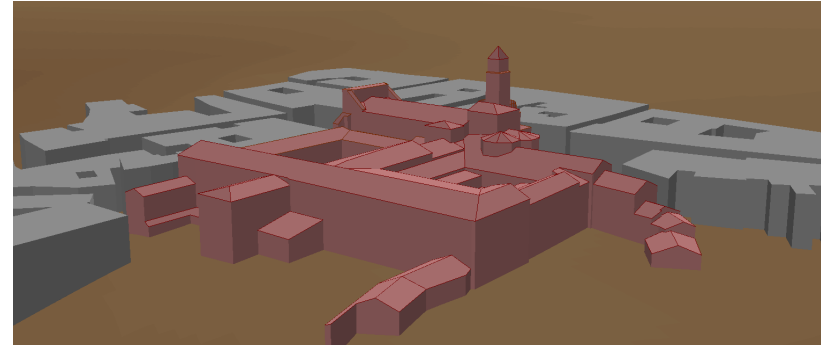

Figure 5. LoD2 for the case study of Tolentino's Church

\subsection{Representation of Cultural Heritage}

The necessity to document cultural heritage is well known and acknowledged at international level. For this reason, several cataloguing systems are developed at both national and international level in order to inventor the cultural heritage items. In this scenario, the aims of documentation consist mainly in preservation and in some studies and analysis about cultural heritage. The documentation is a fundamental tool in order to increase resilience. The concept of resilience related to $\mathrm{CH}$ has spread over the last years.

To model the ResCult EID, it is essential to consider the classification of the cultural heritage. Different categorizations are possible, because they are developed at national or international levels and sometimes they are articulated in different catalogues having different scope or, simply, a different level of updating.

For these reasons, the project has analysed the most update catalogue systems in Europe, Italy, France and Germany (Country of project partners), and starting from these systems, the Rescult classification of $\mathrm{CH}$ was made, in order to integrate national and international classifications.

In the European scenario, the UNESCO Classification describe in the Convention Concerning the protection of the World Cultural and Natural Heritage: The General Conference of the United Nations Educational, Scientific and Cultural Organization meeting in Paris from 17 October to 21 November 1972, at its seventeenth session, (...) the definition of $\mathrm{CH}$ (UNESCO, 1972). In the first article it defines monuments, group of buildings and sites. However, for the ResCult DM, this classification is dated and it is not sufficiently updated and complete.

In this regard, it is integrated for the considered RESCULT classification, by adding the more recent definitions of $\mathrm{CH}$ items in the UNESCO documents. In particular: the concept of Cultural Landscape (1992), combined works of nature and humankind (UNESCO, 1992; WHC-92/CONF.002/12 point IV); and Intangible $\mathrm{CH}$ (the more recent definition of $\mathrm{CH}, 2003$ ) (UNESCO, 2003).

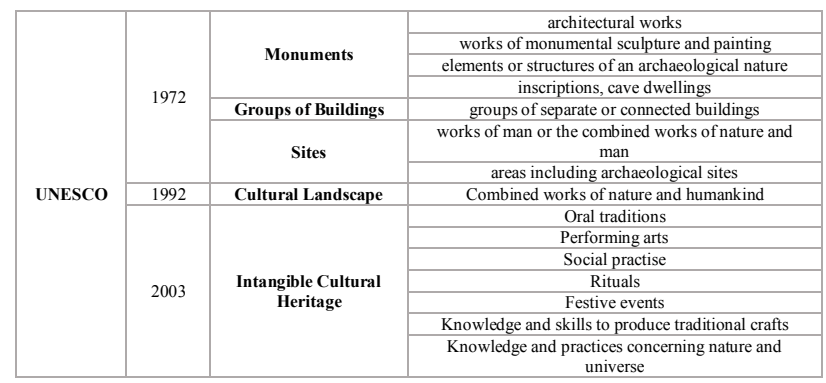

Table 1. UNESCO classification of $\mathrm{CH}$

Successively, it was analysed the national level. Starting from Italy, it was investigated the $\mathrm{CH}$ classification. The catalogued entities, in Italy, belong to the Ministero per i Beni e le Attvità culturali (MIBACT, Ministry of Cultural heritage and Activities).
To define the EID Conceptual Model, it was necessary to study and compare every classification by these different catalogue authorities. In the MIBACT, several different inventory organizations exist and very often the most recent classifications are based on the previous ones, so that they are already included in the most recent classification. The first one investigated, by ICCD (Central Institute for the Catalogue and Conservation), is the most recent in Italy, often including the classes and values defined by the further Italian classifications and it is implemented in the SIGECweb platform (General Information System of Catalogue). This classification is used to catalogue the Italian $\mathrm{CH}$ on an open web platform available from 2012: Open Iccd SIGECweb. It is a data-bank to manage more than 2.300 .000 web-data-sheets about $\mathrm{CH}$. This system permits the sharing of data thanks to the application and shows datasets referring to different types of content. It also includes Cultura Italia, another classification system. The ISCR (Italian Preservation and Restoration Institute) classification manages the SIT (Territorial Informative System) catalogue system which contains the Risk Map, a map that can represent $\mathrm{CH}$ as georeferenced points, on the base of two factors of risk: vulnerability and territorial dangerousness. This archive is less recent than the first one and the biggest limit lies in the fact that few $\mathrm{CH}$ are referenced on the map.

Moreover, Vincoli in Rete is a project, made by the ISCR, oriented to the development of services dedicated to any kind of users for consulting and managing the cultural heritage protection documents. The data used are taken from the other MiBACT data-banks. The PaBAAC (General Directorate for fine arts, architecture and contemporary art) classification defines the Protected $\mathrm{CH}$. This classification is already included in the ICCD classification. The last one Italian classification is the BeAP (General Directorate for fine arts and landscape) one. The BeAP manages the Web Georeferenced Map SITAP, where the restrictions are defined, categorized in Historic and Ethnoanthropological $\mathrm{CH}$.

As already mentioned the ICCD classification is the most recent one in Italy, and the values of the previous classifications are often included in it. For these reasons, the employed classification is inserted in the ResCult DM.

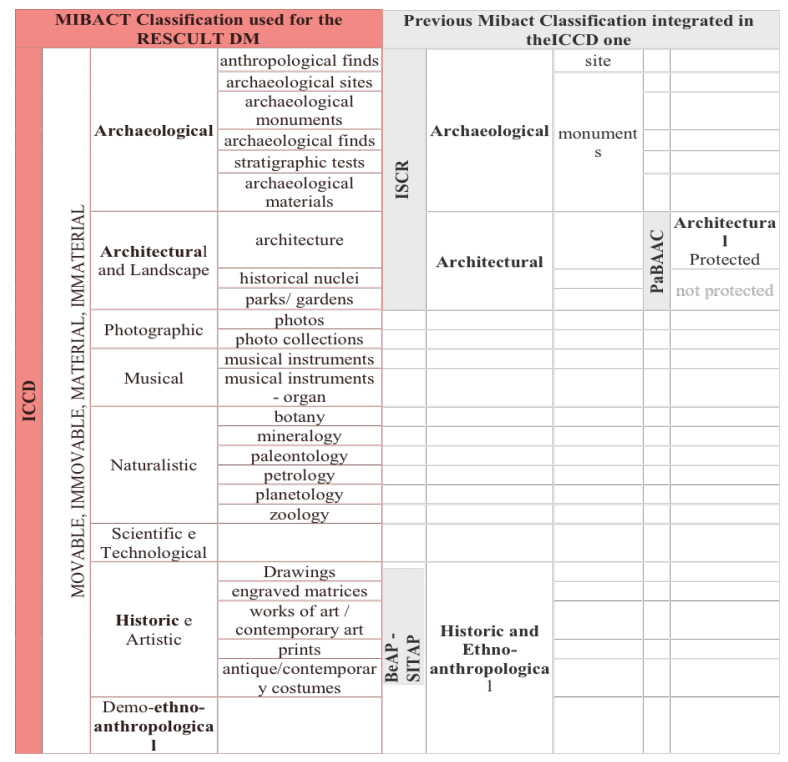

Table 2. MIBACT classification of $\mathrm{CH}$

In France, the situation about $\mathrm{CH}$ cataloguing and standards differs greatly from the Italian MIBACT system. 
The Department of Architecture and Heritage is comprehended in the Ministry of Culture and it deals with the inventory of Cultural Heritage. The $\mathrm{CH}$ databases are administered by the Department of studies, documentation and inventory and these databases are improved with the help of the General Inventory of Cultural Heritage, Historical Monuments, and the Media Library of Architecture and Heritage. The cataloguing databases (DB) form a coherent whole organized according to the following principle:

- Architecture DB (Name of the DB: "Mérimée"), lists buildings in which movable works studied in the DB Palissy can be kept. - Furniture DB (Name of the DB: "Palissy"), lists of movable objects, whose conservation building can be studied in Mérimée.

- Images $D B$ (Name of the DB: "Memory"), contains still images, some of which illustrate the works of Mérimée and Palissy DBs as well as the Thesaurus records.

- Bibliography DB (Name of the DB: "Archidoc"), contains bibliographic records which can also be related to the records of Mérimée and Palissy.

In France also exist the Joconde database, it is a digital inventory of the works of national museums which catalogue the movable cultural heritage. Nowadays, the only available standard for museums and artworks is the CIDOC CRM, but it's not declared if it is used for the Joconde system.

In Germany, there is not a classification system of $\mathrm{CH}$, it is possible to find only the Normative/Law that considers the history of the monuments and some rules of preservation, restoration and protection of $\mathrm{CH}$. Each German Region is responsible for the cultural heritage present in it, and some of them independently fill in a list of the more important monuments, together with some information mainly connected to their management (e.g. phone number, property, etc.). However, they are not included in databases, nor described through cataloguing sheets. For representing German monuments, the UNESCO classification can be used.

Finally, the ResCult classification derives from the previously described catalogues, these were integrated in a unique list, an integration of national and international levels.

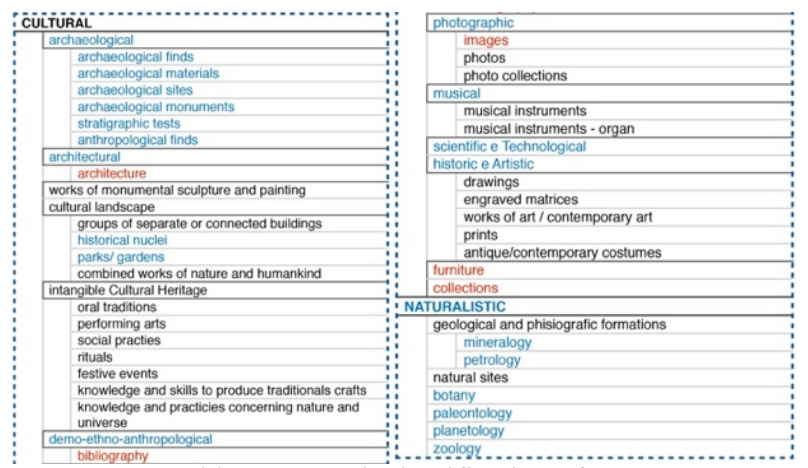

Table 3. ResCult classification of $\mathrm{CH}$.

\subsection{Representation of Hazards and Risks}

In order to realise the ResCult DM, also some existing standards about classifying risks and hazards or prevention and management were considered. After analysing them, the more updated and detailed ones were chosen as a reference for being included in the DM. Before this research it was investigated the meanings of risk and hazard, defined by UNISDR in the DDR (Par 2.) (Risk=hazard impact*probability of occurrence) (UNISDR, 2009). There are lots of researches in the field of disasters and crisis management. In this regard, there are some classifications of disasters and hazards described below.
For example, in an article published by UNESCO entitled "Managing Disaster Risks for World Heritage" (UNESCO, ICCROM, ICOMOSIUCN, 2010) they categorized hazards as is showed in the Figure 6.

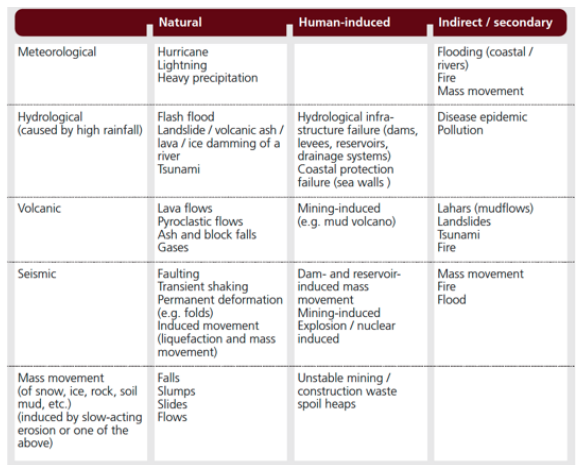

Figure 6. Relationships of natural hazards and human-induced hazards

More recent researches divided disasters into two categories: Natural and technological (or manmade) disasters according to international federation of red cross and red crescent, as is here repeated for having a general framework:

- Natural hazards, are naturally occurring physical phenomena caused either by rapid or slow onset events;

- Technological or man-made hazards, complex emergencies/conflicts, famine, displaced populations, industrial accidents and transport accidents.

Centre for Research on the Epidemiology of Disasters (CRED) and Munich Reinsurance Company (Munich RE) also classified natural disasters. Here the version updated in 2009 (CRED, 2009) is reported in Figure 7.

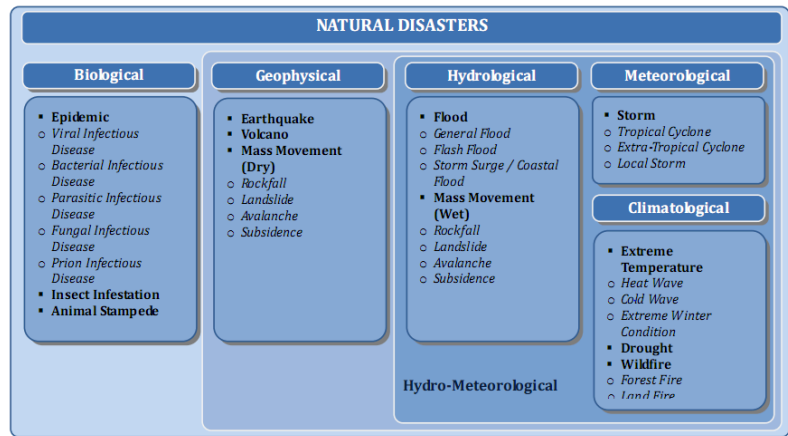

Figure 7. CRED natural disaster classification (CRED, 2009)

In the INSPIRE data model a classification is proposed, borrowing the CRED classification of natural disasters.

An even more update classification derives from the work of Integrated Research on Disaster Risk (IRDR). This research group was established by the International Council for Science (ICSU) in 2010 in cooperation with the International Social Science Council (ISSC) and the United Nations International Strategy for Disaster Reduction (UNISDR). Its aim was to address hazards and make informed decisions on actions to reduce their impacts. The work of IRDR developed a new integrated classification (published in 2014) (IRDR, 2014). The resulting document is employed as main reference for the glossary of the International Disaster Database (EM-DAT) published by the CRED, in which also the technological hazards are included.

Finally, the ResCult classification of risks and hazards derives from these previous analysed classifications, and it includes natural and technological disasters. 

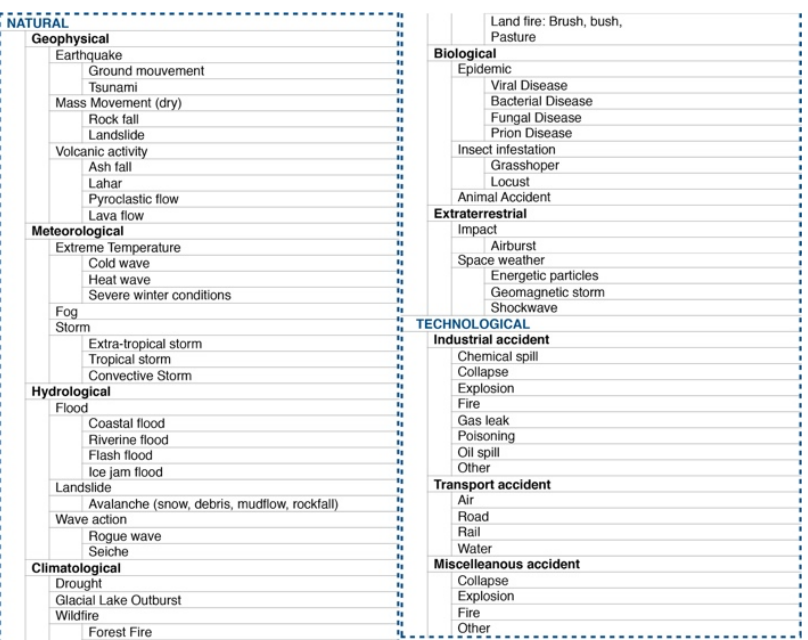

Table 4. ResCult risks and hazards classification

\section{EID DESIGN: A DATABASE PLATFORM FOR EMERGENCY PLANS}

The initial issues to be solved, as previously told, have therefore determined the consequent structure of the EID in order to operate in a unique framework.

The most important issue is to ensure an effective interoperability of the database, then to asset a general methodology for risk analysis, combining the $\mathrm{CH}$ representation with the hazard and risk representation. As the EID has to be visible, accessible and available for everyone, it has been foreseen the use of free and open data in some cases and structured data in others.

In particular we tried to meet these needs using existing standard models for object classification and 3D model mapping (INPIRE and CityGML), defining a particular extension of standard model for $\mathrm{CH}$ and Risks and proposing a new methodology able to connect $\mathrm{CH}$ and Risks.

Moreover, according to international standards, a designing process has been used for EID modelling from real word to database implementation (Figure 9).

The process starts from the external model that contains the analysis of the perceived reality of the application domain by users, stakeholders and actors described in natural language (high-level language) (Laurini, Tompson, 1992).

This model has to be formalized in a conceptual model that is a graphical representation of the application domain using entities and relationships among them. The conceptual model can be understood all over the world from various experts and users.

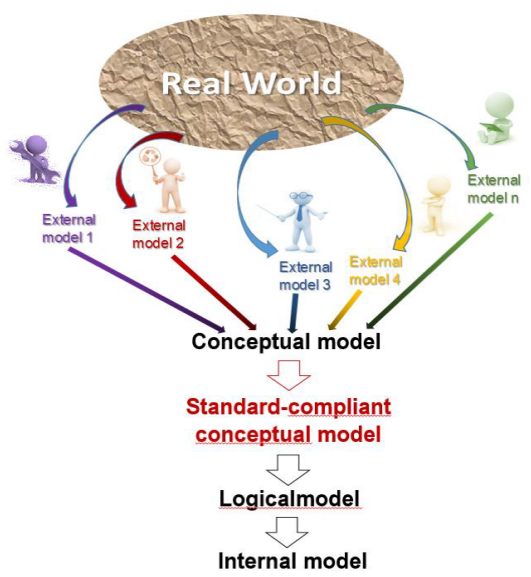

Figure 9. A framework for the design of an information system adapted from (Laurini, Tompson, 1992)
Then the logical model is a schematization of conceptual model for a particular kind of computer implementation in a DB management system and, at the end, the internal model is the DB implementation in a low-level language, but the users usually don't access to this kind of model.

\subsection{The extension of the INSPIRE data model}

Actually, there have already been some previous researches which have proposed extensions to the cartographic standards here considered. In particular, two studies for extending CityGML (Costamagna, Spanò 2012, Noardo 2017) and another one extending the INSPIRE data model (Fernàndez-Freire et al., 2013); when possible they have been taken into account for the development of the EID.

The ResCult data model, as INSPIRE extension, in a nutshell consists of mutual connections among the three topic themes ("Buildings" as INSPIRE Object, "Protected Site" and "Natural Risk Zone") each of them conveyor of semantic and geometric contents compliant to the several existing standards (Figure 10). For supporting the assessment analysis preventing risks and hazards, it is necessary to relate some entities of the "ProtectedSite" theme with further INSPIRE objects represented in other themes.

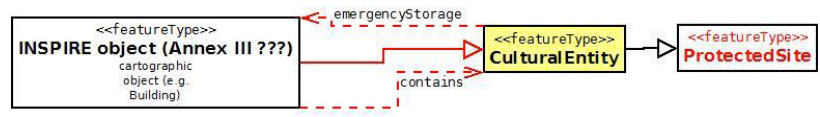

Figure 10. UML model of the new relationships between ProtectedSite and other cartographic objects

First of all, it is necessary to represent the relationship between any cartographic object, represented especially in the INSPIRE data model, Annex III (for example, the "Building" theme), and the "Protected site", which can be composed by a number of further cartographic objects, being themselves cultural objects or not. The class "CulturalEntity", proposed by Fernández-Freire et al. (2013), is kept in the Data Model, but a different relation is established to "ProtectedSite": a direct subclass relationship links "CulturalEntity" to "ProtectedSite", so that "CulturalEntity" inherits all the attributes of the class "ProtectedSite".

Three main relationships are then established between the class CulturalEntity and any cartographic object (usually derived from INSPIRE data model, annex III) (Figure 11):

- An "is-a" relationship, when the cartographic object (e.g. a Building, or a street, or a bridge, and so on) is itself a cultural entity to be protected and preserved;

- A relationship "contains", which is useful to represent any case in which the container (e.g. the Building, the street, etc.) do not deserves to be protected for its own value, but it hosts valuable cultural objects to be protected and preserved (e.g. archives, museums, other mobile cultural heritage, etc.), whether tangible or intangible assets.

- The third relationship is "emergencyStorage", since it is common to establish a storage site where to move cultural objects in case of emergency (this is obviously valid for movable cultural heritage).

The three relationships can simultaneously exist (e.g. a Building can have a high architectonic value, can host a picture collection and can be selected and prepared to host further cultural objects in case of emergency regarding other sites).

In detail, to describe the model extension, it's necessary to start from the core class of the Protected Site data model, that is the "Protected Site" feature type, as it is specified in the Protected Site full data model. 


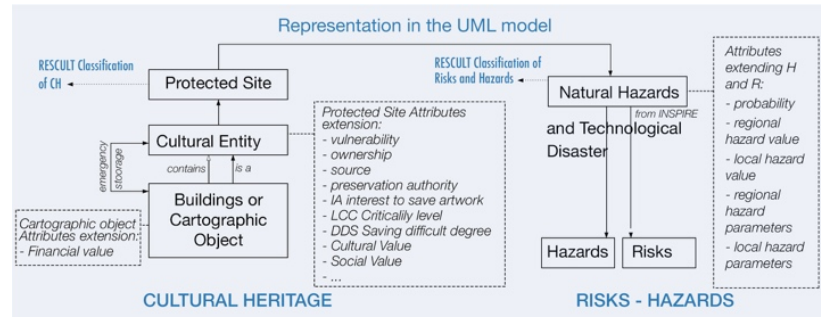

Figure 11. Simplified schema of the EID conceptual model with the three main topic themes

Some attributes are added for being used in the risk and hazard assessment analysis, or for archiving the results of such analysis in the class itself, so that they can be immediately available for the operators managing the disaster damages prevention.

Some other data types, conversely, become more complex.

For example, as a first extension, the attribute vulnerability is no more a simple characterString, but it is specified in a dedicated datatype and the same for the attributes ownership and documentation.

As second extension, there has been the addition of attributes to the "ProtectedSite" feature type itself (Figure 12).

They regard the parameters involved in the analysis, and other data useful to the management of the entity (preservation authority, criticality level, degree of difficulty in saving, priority of saving, cultural value, social value, specific vulnerability structure, etc.), so that they can be available to operators to compute or interpret the results of the vulnerability and priority assessment of each protected site or object. Whereas concerning the "NaturalRiskZones" theme a hierarchical codelist has been realized, including this classification extended with the subcategories of epidemic risks and the other values in addition to the man-made and technological risks as new category values, with related subcategories.

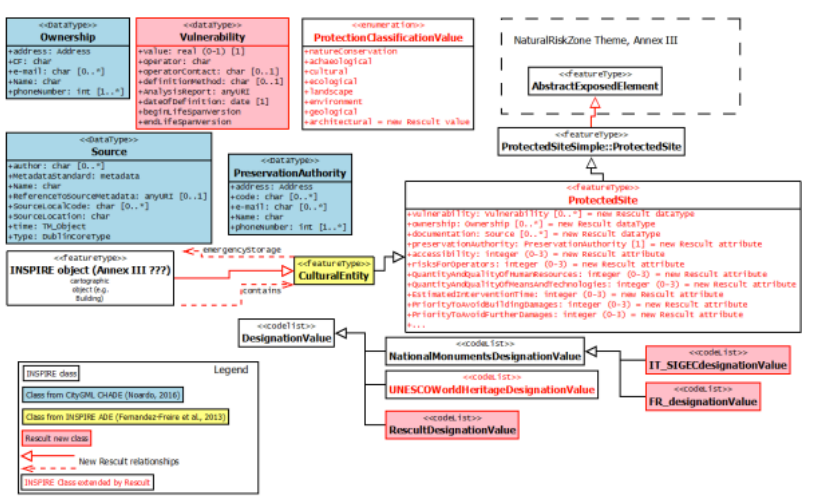

Figure 12. Synthetic schema of the main extensions to the INSPIRE data model (Protected Site theme, INSPIRE themes Annex I)

4.1.1 The extension of the cultural heritage classification: In the INSPIRE "ProtectedSite" theme, some classification values for cultural heritage items and sites are already present. However, for this DM the existing classifications have been integrated with further values deriving from the updated national classifications and from the most updated UNESCO classifications (Par. 3.2) (Figure 13).

The ProtectionClassificationValue enumeration lists the possible reasons behind protection, which imply different preservation methods and measures for each kind of protected object. For this EID, the value "architectural" is added. The values justifying the protection for cultural heritage are therefore:
- Archaeological, which regards the archaeological sites and objects;

- Landscape, which usually include large portions of land, with specific characteristics to be preserved;

- Architectural, which regards any sort of building or construction with high architectonic value;

- Cultural, for all the other sites having some cultural value, difficult to be included in the previous categories (e.g. mixed built and natural heritage, a site connected to intangible heritage, and so on).

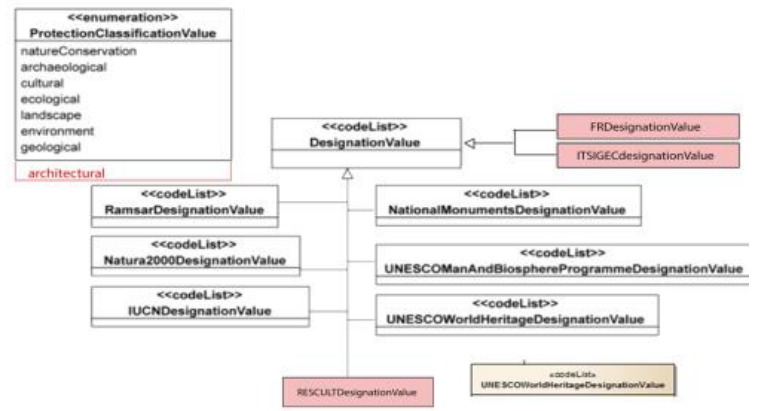

Figure 13. Extension of the classification values for cultural heritage.

In particular, for Italy, the classification proposed by ICCD is included as a codelist.

Another extension to the INSPIRE data model is the inclusion of the most updated values of the UNESCO classification in the "UNESCOWorldHeritagDesignationValue".

4.1.2 The extension of the Natural Risk Zone: A second extension, necessary to effectively realize the EID, is the extension of the INSPIRE "NaturalRiskZones" theme. The foreseen classes are already quite sufficient to represent the risk and hazard problems. However, some attributes must be added to the existing classes, and some new code lists and DataTypes are necessary for representing the information needed for the subsequent analysis.

As some of the added attributes are quite complexes, so new DataTypes became necessary. The new DataTypes archiving the parameters useful to assess a risk include the parameters useful to assess the flood, earthquake and fire risk, which are the ones selected for the project to be analyzed. The list could be further enhanced for considering also different kind of hazards.

All the parameters will have the values: high/medium/low and for completing them a new enumeration was also added.

Finally, also the theme "NaturalHazardClassification" has been extended and it includes the classification of risks proposed by the CRED classification and accepted by UNESCO (CRED, 2009).

\section{CONCLUSIONS}

After selecting and analyzing the existing standards, classifications and requirements, an extension to the INSPIRE data model was here proposed in order to represent the information useful to increase the resilience of the $\mathrm{CH}$, enable decision makers to understand the risk of damage to cultural assets and support operators during emergencies or postemergency situations.

Many attributes and data included in the extension are connected to the hazards fire, flood and earthquake, selected for the project to be better investigated. However, in future work, there is the possibility to further enhance these parameters in order to be useful also for other hazard types, included in the hazard 
classification code list, employing a similar mechanism, which is described in this document. A connection between different INSPIRE themes is established, which are not directly related in the INSPIRE data model. This is fundamental in order to relate different kind of information about the same studied object. Further development will also regard the creation of an interface for the DB, the modeling of the geometry for the case studies selected by recognized macro elements included in the classification of the Getty's architectural elements and the implementation of the DB with the data of the three cases study selected (Santa Maria dei Miracoli, for flood hazard, and Tolentino's Church, for earthquake hazard, in Italy and the Museum of Prehistory of the Gorges du Verdon, for fire hazard, in France).

\section{ACKNOWLEDGEMENTS}

POLITO team would like to thank the other ResCult partners SITI, Corila/IUAV, UNISDR, SDIS04, TUB and the participants at the first User Forum, that took place in Venice on the $29^{\text {th }}$ of Novemver 2017, thanks to it was possible obtain a lot of feedback in order to redefine and improve the ResCult IED (User Forum Agenda at the link: https://www.rescult-project.eu/newsevents/first-user-forum-in-venice/).

\section{REFERENCES}

Costamagna, E., Spanò, A. (2012). Semantic models for architectural heritage documentation. In: EuroMed 2012: Progress in Cultural Heritage Preservation, LNCS Book Series, Springer Verlag ISBN: 978-3-642-34234-9 DOI: 10.1007/978-3-642-34234-9_24 pp. 241-250.

Costamagna E.; Spanò A. (2013) CityGML for Architectural Heritage, In: Lecture Notes in Geoinformation and Cartography.. Developments in Multidimensional Spatial Data Models / Abdul Rahman, A.; Boguslawski, P.; Gold, C.; Said, M.N. (Eds.) Springer, pp 19, pagine 219-237, ISBN: $\mathbf{9 7 8 3 6 4 2 3 6 3 7 8 8}$

Council of Europe, 2005. Council of Europe Framework Convention on the Value of Cultural Heritage for Society. Council of Europe Treaty Series - No. 199. Faro, 27.X.2005.

CRED, 2009. Disaster Category Classification and peril Terminology for Operational Purposes, Common accord. Centre for Research on the Epidemiology of Disasters (CRED) and Munich Reinsurance Company (Munich RE), Working paper, October 2009.

Drdácký, M., Binda, L., Herle, I., Lanza, L.G., Maxwell, I., Pospíšil, S., (2007). Protecting the Cultural Heritage from Natural Disasters-Study, European Parliament, Directorate-General for International Policies of the Union, Policy Department Structural and Cohesion Policies Culture and Education, Brussels, European Parliament, February 2007.

EM-DAT disaster classification: http://www.emdat.be/classification Accessed on $06 / 10 / 2017$

European Commission, 2010. Commission Staff Working Paper, Risk Assessment and Mapping Guidelines for Disaster Management. Brussels, 21.12.2010. SEC (2010) 1626 final.

Fernández-Freire, C., del-Bosque-González, I., Vicent-García, J. M., PérezAsensio, E., Fraguas-Bravo, A., Uriarte-González, A., Fábrega-Álvarez P., Parcero-Oubiña, C. (2013). A Cultural Heritage Application Schema: Achieving Interoperability of Cultural Heritage Data in INSPIRE. IJSDIR, 8 , pp. 74-97.

ICOMOS, 1998. International Charters for conservation and restoration. Stockholm, September $11^{\text {th }}, 1998$.

INSPIRE Directive website: http://inspire.jrc.ec.europa.eu/ Accessed on 06/10/2017.

INSPIRE, 2013. D2.8.III.2 INSPIRE Data Specification on BuildingsTechnical Guidelines. http://inspire.ec.europa.eu/id/document/tg/bu Accessed on $06 / 10 / 2017$.

INSPIRE, 2014a. D2.8.III.12 Data Specification on Natural Risk Zones Technical Guidelines. Accessible at https://inspire.ec.europa.eu/id/document/tg/nz Accessed on 06/10/2017.
INSPIRE, 2014b. D2.8.I.9 Data Specification on Protected SitesProtected Sites - Technical Guidelines. Accessible at

https://inspire.ec.europa.eu/id/document/tg/ps Accessed on 06/10/2017.

Integrated Research on Disaster Risk. (2014). Peril Classification and Hazard Glossary (IRDR DATA Publication No. 1). Beijing: Integrated Research on Disaster Risk. Accessible at http://www.irdrinternational.org/wpcontent/uploads/2014/04/IRDR_DATA-Project-Report-No.-1.pdf Accessed on 12/01/2018.

Laurini, R., Thompson, D., 1992. Fundamentals of spatial information systems (Vol. 37). Academic press.

Noardo, F. (2017). A spatial ontology for architectural heritage information. In: Grueau, C., Gustavo Rocha, J., Laurini, R., GISTAM 2016 - Revised Selected Best Papers, CCIS Book Series, Springer International Publishing, pp. 143-163. ISBN 978-3-319-62617-8. DOI: https://doi.org/10.1007/978-3-319-62618-5 9

OGC, 2012. OGC City Geography Markup Language (CityGML) Encoding Standard. Approval Date: 2012-03-09, Publication Date: 2012-04-04, External identifier of this OGC

http://www.opengis.net/spec/citygml/2.0, Reference number of this OGC: OGC 12-019, Version: 2.0.0. Editors: Gröger, G., Kolbe, T.H., Nagel, C. Häfele, K.H.

OGC, 2014. Modeling an application domain extension of CityGML in UML - OGC Best Practice.

https://www.google.it/url?sa=t\&ret=j\&q=\&esrc $=$ s\&source $=$ web\&cd $=2 \& v e d=$ 0ahUKEwj4y5iBvpDWAhXmCcAKHbFPCi4QFgg4MAE\&url=https\%3A\% 2F\%2Fportal.opengeospatial.org\%2Ffiles\%2F\%3Fartifact_id\%3D49000\&us g=AFQjCNEB3iO-epWbnOP_ynrw08VMEdyzsw (1 September 2017).

ResCult website: https://www.rescult-project.eu Accessed 10/02/2018.

SIGECWEB website:

http://www.sigecweb.beniculturali.it/it.iccd.sigec.axweb.Main/ Accessed 10/02/2018.

UNESCO 1972. Convention Concerning the Protection of the World Cultural and Natural Heritage. The General Conference of the United Nations Educational, Scientific and Cultural Organization meeting, seventeenth session, Paris 17 October - 21 November 1972. Available at http://whc.unesco.org/en/conventiontext/ Accessed 04/09/2017.

UNESCO, 2003. Convention for the Safeguarding of the Intangible Cultural Heritage 2003, Paris, 17 October 2003. Available at http://portal.unesco.org/en/ev.php-

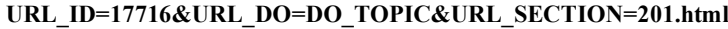
Accessed on 04/10/2017.

UNISDR, 2009. Terminology on Disaster Risk Reduction. ISDR, International Strategy for disaster reduction. United Nations.

UNESCO, ICCROM, ICOMOS IUCN, 2010. Managing Disaster Risks for World Heritage. Published in June 2010 by the United Nations Educational, Scientific and Cultural Organization.

UNISDR, 2017. Disaster-related Data for Sustainable Development. Sendai Framework for Disaster Risk Reduction 2015-2030. Data Readiness Review 2017. Global Summary Report.

United Nations, 2015. General Assembly. Seventieth session. Agenda items 15 and 116. Distr.: General 21 October 2015. At

http://www.un.org/sustainabledevelopment/sustainable-development-goals/ Accessed on 09/02/2018.

WHC-92/CONF.002/12, 1992. United Nations educational, scientific and cultural organization, convention concerning the protection of the world cultural and natural heritage, World Heritage Committee. Sixteenth session, Santa Fe, United States of America, 7-14 December 1992. 